\title{
Sweet Syndrome
}

National Cancer Institute

\section{Source}

National Cancer Institute. Sweet Syndrome. NCI Thesaurus. Code C85177.

A rare syndrome characterized by fever, skin papules and plaques, and leukocytosis.

Morphologically, the skin lesions show neutrophilic infiltrates and dermal edema. It may

occur in the absence of underlying conditions. It may also be associated with the

presence of cancer or may be a side effect of medications. 